\title{
Pedagogical Conditions for the Formation of Leadership Qualities of Adolescents in a Children's Public Organization
}

\author{
Liliya Ibragimova \\ Faculty of Pedagogy and Psychology \\ Nizhnevartovsk State University \\ Lenin str. 56, 628605 Nizhnevartovsk \\ Russian Federation \\ e-mail: laibra@yandex.ru \\ Asil Salavatova \\ Faculty of Pedagogy and Psychology \\ Nizhnevartovsk State University \\ Lenin str. 56, 628605 Nizhnevartovsk \\ Russian Federation \\ e-mail: asil-06@list.ru \\ Olesya Istrofilova \\ Faculty of Pedagogy and Psychology \\ Nizhnevartovsk State University \\ Lenin str. 56, 628605 Nizhnevartovsk \\ Russian Federation \\ e-mail: ol_istr@mail.ru
}

\begin{abstract}
This article describes the pedagogical conditions for the formation of leadership qualities of adolescents in a children's public organization: the systematic involvement of adolescents in specially organized activities aimed at acquiring leadership experience; the use of social design technology in the activities of the children's public association with the provision of every teenager the opportunity to implement various positions of the association members (from the performer to the organizer); the implementation of systematic pedagogical monitoring of the dynamics of development of leadership qualities of adolescents. This is due to the fact that modern reality, characterized by an increase in the demands placed by society on the development and upbringing of the individual, capable of social transformations, competitive in various situations, focused on effective interaction with state and public organizations, requires the upbringing and development of leadership qualities among adolescents. The content of the concept of "pedagogical conditions." The analysis of the scientific works of researchers on the problem of identifying pedagogical conditions for the effective formation of leadership qualities in adolescents is presented. The importance of the multicultural environment of a children's public organization in the formation of leadership qualities of adolescents is emphasized. It was recommended the creation of certain pedagogical conditions to ensure the formation of leadership qualities of adolescents in a children's public organization, such as the use of innovative pedagogical technologies, primarily personality-oriented education, and the improvement of the organization's activities for the social adaptation of adolescents.
\end{abstract}

\section{Introduction}

Intensive changes and transformations occurring in recent decades in the life of not only Russians, but also Europeans, determine the formation of an active personality in the development of social reality.

Modern processes taking place in civil society are called upon to provide conditions for the self-realization of both individuals and collectives. The problem of the development of Russian society in modern conditions is due to the formation of creative principles in the behavior of each person and the overcoming of social passivity

The emergence and development of multicultural education is changing the position and approaches in education and training, taking into account ethno-pedagogy, ethnopsychology and innovative processes. Multicultural education is the process of assimilation by the younger generation of ethnic, national (Russian) and world culture for the purpose of spiritual enrichment, the development of planetary consciousness, the formation of readiness and the ability to live in a multicultural multi-ethnic environment. The concept of multicultural education follows from the well-known concept of "education". Namely, education - one of the areas of social and cultural life, is interpreted as a comprehensive cultivation of a moral and free personality, able to defend its point of view and its values (Pogrebnaya et al. 2019). Basics of multicultural education: culture, education of 
peacefulness, globalism; integration processes in education, pedagogical and regional-ethnic culture of the people, respect for each ethnic group with its specific mentality.

An analysis of modern scientific literature, various ideas and concepts of scientists and researchers, the realities of the pedagogical and sociocultural situation proves that up to now the possibilities of children's associations in creating social and pedagogical conditions for the personal growth of their members in a multiethnic environment are not fully used.

To ensure the formation of leadership qualities of adolescents and obtain an effective result of this process, certain pedagogical conditions must be created in the children's public organization:

1. The use of innovative pedagogical technologies, primarily, personality-oriented education, including:

- taking into account age, psychological and pedagogical characteristics of adolescents;

- the organization of positive emotional communication in the organization, the implementation of an individual approach, the creation of a developmental environment that meets the needs of the adolescent, the saturation of the educational process with various activities that model the way the adolescent behaves in various situations;

- $\quad$ use of the principles of social learning

2. Improving the content of the organization for the social adaptation of adolescents, including:

- psychologization of the educational process, its comprehensive socio-psychological, pedagogical support, which allows you to study and take into account the personality characteristics of a teenager, due not only to its nature-like features, but also to the impact of the surrounding multicultural environment of the educational institution;

- inclusion of participants in a children's public organization in multifaceted, personally and socially significant activities;

- management of the most multicultural educational environment of a children's public organization;

- $\quad$ organization of scientific management of this process in a multicultural educational environment of the organization, which, in turn, requires a model presentation and software for this activity.

Leadership has a more complex nature and depends not only on the personality traits, but also on its place and position in the structure of intra-group relations. Observations and practice show that the leader in the group is one who clearly understands the tasks, sees the ways to solve them, acts at a higher level than the rest of the group. As a special social and age group in the structure of society and due to lack of life experience, lack of legal literacy, lack of values and attitudes, young people are especially susceptible to various types of negative social trends (Bauer et al. 2018). It should also be noted the importance of information culture in the formation of leadership qualities of adolescents, since it is often difficult for a modern person among a large number of information flows to navigate in its diversity (Ibragimova and Scobeleva 2018).

\section{Definition of concepts}

For the successful development of leadership qualities of adolescents in a children's public association, it is necessary to determine the pedagogical conditions that will contribute to this process.

The concept of "pedagogical conditions" causes a large number of disputes among researchers on the content and on the appropriateness of its use. The analysis of pedagogical conditions in pedagogy is given a lot of attention. For example, Vygotsky (1960) argued that it was necessary "to create in advance the conditions necessary for the development of the corresponding mental qualities, although they were not yet 'ripe' for independent functioning".

Pedagogical conditions represent the circumstances or conditions specially created by teachers in order to systematically help self-development and professional improvement of a person to the best of his ability and in accordance with his social ideal. In this understanding, the key role of the teacher is clearly visible. Pedagogical conditions are the pedagogical circumstances accompanying the factor that contribute to (or counteract) the manifestation of pedagogical laws caused by the action of factors.

The understanding of pedagogical conditions presented by Borytko (2001) deserves attention. Under the pedagogical condition Borytko understands an external circumstance that has a significant impact on the course of the pedagogical process, to one degree or another consciously designed by the teacher and involving the achievement of a certain result.

Scientists consider the pedagogical conditions as a combination of the possibilities of the educational and material-spatial environment, the use of which helps to increase the effectiveness of the holistic pedagogical process (Khushbatov 2015). 
We find a different understanding of pedagogical conditions in Andreev (2000). The scientist believes that pedagogical conditions are not circumstances, but the result of "purposeful selection, design and application of content elements, methods (techniques), as well as organizational forms of training to achieve goals". As a result, we suggested that the process of developing leadership qualities of adolescents in a children's public association will be effective if:

- $\quad$ systematically involve adolescents in specially organized activities aimed at gaining leadership experience;

- use social design technologies in the activities of the children's public association, providing each teenager with the opportunity to implement various positions of the association's members (from the performer to the organizer);

- systematically carry out pedagogical monitoring of the dynamics of leadership development of adolescents.

\section{Justification of pedagogical conditions}

The following is the rationale for each of the conditions.

1. The systematic involvement of adolescents in specially organized activities aimed at gaining leadership experience.

The development of leadership qualities of a teenager in a children's public association is largely determined by the content of the activity in which the team is included. The activity and its content are the subject of research by many scientists. Pedagogy does not consider activity as an independent pedagogical phenomenon. It is dominated by the study of specific types of activities: educational, social, sports, etc. The definition of the very category of "activity" is borrowed from philosophy and psychology, which initially emphasized the relationship of activity with elements such as knowledge, operation, goals, motives, consciousness, signs, meaning, meaning, etc.

In the disclosure of the category of activity, philosophers call the subject that a person highlights his own activity. The main constructive element of this selection is the "task". There are other points of view when activity is understood as labor and thinking.

The following is considered to be the most universal, although not a complete definition of the concept of "activity": activity is a specifically human form of active attitude to the world, the content of which is an expedient change and transformation of this world based on the development and development of available forms of culture.

Note that the common in all definitions is the understanding of activity as a form of an active relationship of a person to actual activity.

The unshakable postulates of psychological and pedagogical science include the fact that a person's personality develops and is formed in the system of social relations depending on his living conditions, but, first of all, in the process of activity and communication.

The pupil as a carrier of social experience does not just master the sum of knowledge, information, samples, skills, but learns the ways of activity and communication, the result of which he is. The main element of the psychological and pedagogical mechanism of social experience is activity. In order for a person's activity to be called socially significant (useful to the society in which the individual is located), it must be a carrier of the totality of qualities necessary for socially significant activity. In our study, activity is understood as a type of activity inherent only in humans, characterized by the following features:

- $\quad$ subject - carrying out the implementation of activities;

- object - opposing the subject;

- the subject on which the activity of the subject is directed;

- technology of the subject in this situation;

- tools used by the subject in the process of implementation of activities;

- result - the subject changed during the course of the activity.

Activity makes certain demands on the subject. "any personality traits," writes Platonov (Platonov and Adaskin 1996) develop only in the process of the activity for which they are needed, and in the process of which they are therefore activated. Not any activity develops leadership qualities, but only one that puts a teenager in a certain attitude to the collective of people. It is the diverse activity aimed at acquiring leadership experience that contributes to the development of leadership qualities. If the activities of adolescents are one-sided, for example, reduced primarily to solving intellectual problems, then the possibilities for developing leadership qualities will 
be limited. In a children's public association, adolescents gain certain knowledge, develop leadership skills in various types of activities they offer. A teenager consciously chooses for himself that position in which his abilities and desires are most fully realized.

In a children's association, a teenager, on an equal footing with life experience peers, can choose the forms and types of activities available to him, how to implement them and, together with others, experience satisfaction from the result of his efforts. The teenager in the process of activity learns himself, improves himself and develops his leadership qualities.

Thus, since it is the activity that nominates the leader, through specially organized activity it is possible to provide favorable opportunities for the success of those adolescents who have the potential to influence their comrades - members of the children's public association.

The development of an organization as a team is characterized by a constant change of leaders depending on the type, nature and content of activities, which provides each member of the organization with the opportunity to stay in the leadership role and acquire other people's organization skills and self-organization.

In the course of organizing activities, the basic principles of a personality-oriented approach should be implemented: moral and socially useful orientation of activity, voluntariness, democracy and humanism, collectivism and creativity, initiative and initiative, cooperation between children and adults.

2. The use of social design technology in the activities of the children's public association, providing each teenager with the opportunity to implement the various positions of the association's members (from the performer to the organizer).

The above basic principles of a personality-oriented approach determine the possibility of the influence of work on a social project on the development of leadership qualities of adolescents in a children's public association.

Conscious participation in the activities of the association determines the fulfillment by the adolescent of the role of the subject of knowledge, activity, communication, self-development. This, in turn, leads to the need to develop ideas about oneself and others, the ability to build relationships with them, to participate in activities together, to assert oneself and, ultimately, to show their leadership qualities.

The development of a certain social position or the role of a member of a particular association involves mastering certain knowledge and skills. One or another position of a teenager in a children's public association - a dezhkom (duty commissioner), commissioner of affairs, commissioner of the MIG (micro-initiative group), household platoon - promotes the formation of certain personality traits through the implementation of relevant activities.

In our opinion, the use of social design technology will contribute to a change in the role of a teenager in a children's public association, the acquisition of experience in leadership behavior. Note that, in solving the problem of creating pedagogical conditions for the development of leadership qualities of adolescents in a children's social organization, we proceed from the idea that the group may have not one but several leaders, and each of them may have its own sphere of activity.

The experience of our own pedagogical activity and the logic of this study allow us to consider the features of the technology of social design and the development of leadership qualities of a teenager in the process of the children's team working on a socially significant educational project. Social designing is the search for new meanings of social phenomena, relationships and circumstances as a result of anticipating their innovative look and choosing ways of constructive transformation. Translated from Latin, the project means "thrown forward", that is, the plan in the form of a prototype of the object.

In 1998, employees of the Samara Regional Center for Civic Education tested in Russia the socialeducational project "Citizen" used in American schools, the developers of which were scientists from the California Center for Civic Education. It should be noted that the project was not implemented in a matrix, but in accordance with the Russian characteristics of the socio-economic sphere and the development trends of the education system (Pakhomov 2000).

The project method is not fundamentally new in world pedagogy. It arose at the beginning of this century in the United States. He was also called the method of problems and was associated with the ideas of the humanistic direction in philosophy and education. Dewey proposed to build training on an active basis, through the student's expedient activity, in accordance with his personal interest in this knowledge (Pakhomov 2000).

The project method attracted the attention of Russian educators at the beginning of the 20th century. The ideas of project training arose in Russia almost simultaneously with the development of American educators. In 1905, a small group of employees was organized, trying to actively use design methods in teaching practice.

Later, already under the Soviet regime, these ideas began to be quite widely introduced into school, into instruction, but insufficiently thought out and consistently, and by decree of the Central Committee of the AllUnion Communist Party of Bolsheviks (1931), the project method was condemned. Since then, until recently, no more serious attempts were made in Russia to revive this method in school practice. At the same time, he actively and very successfully developed in a foreign school. 
Based on the study and analysis of the works of Krupskaya, dedicated to the pioneer movement, the content, forms and methods of pioneering work in the USSR, we found that back in 1929 Krupskaya, speaking about the socially necessary work of a pioneer organization and school, about the self-government of children, proposed using technology of social design. The teacher believed that self-government should give skills to solve the tasks put forward by life together, by common efforts.

We consider it necessary to quote the recommendations of Krupskaya (1957): "it is necessary for the children to open their eyes to what is being done around. It is important that students not only begin to notice the dirt and puddles standing in the middle of the village, but that they are worried that the village is dirty. Need a habit to approach each business actively. The road is bad, you need to fix the road. The guys understand the meaning of this. It excites them. And the next step: what can we, the team, do to eliminate the mess? And here the extremely important work begins. The measure of their strengths, their skills, the development of a work plan is determined. Not enough skill. Can I get it? What time, which way? What is the best way to distribute work among themselves? They come to the conclusion: we can't do it alone. With whom should one conspire? Who should be involved in the work?".

Recommendations Krupskaya were given at the initial stage of development of a pioneer organization. As we see, these provisions were expressed in connection with the formation of social activity of the pioneers, and they completely coincide with the stages, with the logic of modern social design. Therefore, we can talk about the historical aspect of confirming our assumption about the effectiveness of using social design technology in the development of leadership qualities of adolescents.

The dictionary "Child Movement" gives the following definition of social design - this is a special kind of intellectual activity associated with its value rethinking, experience and self-expression by identifying transformative components of the situation. This is a special type of human relationship to reality, within which he can and should make responsible decisions.

From the point of view of technology, designing is a special procedure, which consists in the information preparation of some changes in reality, in preliminary understanding and description of specific actions aimed at certain results, in identifying additional external and internal resources.

Social designing requires students to analyze the current socio-economic problems of their village, city or district, study the decision-making mechanism by the authorities and form proposals to change the situation in a particular area of social practice, makes it possible to show independence and organizational ability. The social design process includes:

- analysis of the situation of development of a social phenomenon, determination of the problem field, formulation of contradictions, identification of ideas that can help in solving problems;

- development of a standard version of the desired result, corresponding to the project goal and the values of the designers, formulating assumptions about the methods and mechanisms for achieving results, identifying possible obstacles and prospective partners;

- implementation of the project, evaluation of its effectiveness and public recognition.

The technology of social design involves the organization of activities of adolescent members of the children's public association in stages. The structure of work on a social project, the diversity of activities at different stages of work, shows the possibility of live practice with real socially significant results that really affect social reality. Various types of activities in which a teenager can be included when working on a social project have a large reserve for developing leadership qualities. The very fact of a teenager participating in some form of collective activity affects his consciousness, behavior, and the development of value orientations.

As we have already noted, it is equally important that a member of a children's association has the right to choose the type of activity in the design process. The use of social design technology makes it possible for adolescents with different levels of training to show independence and leadership qualities.

Usually, children choose what is more familiar to them, it is clear that they can do well, in which they are already successful. While working on a project, children not only demonstrate previously acquired knowledge and skills, but also improve their skills and master new competencies.

Acting as a commissioner of business (leader, organizer) involves the communication of a teenager with many people. It is important to note that, performing an assignment in one direction or another as part of the work on the project, the teenager becomes the organizer when he needs to attract and mobilize his comrades to complete the work. As a result of the joint socially useful things that a social project involves, the interpersonal relationships of the teenager are strengthened, and the qualities necessary for the leader are developed.

An analysis of the content of the activities of members of a children's public organization in the process of social design shows that adolescents involved in project activities have the opportunity to deepen and update civil knowledge and gain experience in leadership behavior. Participating along with adults in solving vital issues, adolescents are accustomed to be responsible for decisions made. Consequently, the process of social design has 
great pedagogical potential for the development of leadership qualities that are involved in teenagers - members of a children's public organization.

Considering the use of social design technology as a condition for the development of leadership qualities of adolescents in a children's public association, we note the importance of creating a "success situation" by the teacher. The teacher needs to create a situation of success for every teenager. Successfully solving personally significant tasks undertaken by himself, the teenager thus asserts himself, and self-affirmation is most successfully carried out in organizational activities.

Leader puts forward the activity. Therefore, through the use of social designing technology, it is possible to ensure not only situations aimed at team building, but, above all, favorable opportunities for the success of children and their self-development.

The "Success Situation" consists not only of taking into account the teenager's propensities for a certain type of activity, but also training of a member of the squad for new types of activity through individual consultations, trainings, and conversations is necessarily used. All this allows the teenager to master new knowledge, skills, take part in various activities in the design process. Moreover, as follows from the structure of the stages of work on a social project, the implementation of the project offers such activities that are often impossible in ordinary school life.

Belkin (1991) considers the situation of success as a purposeful, organized combination of conditions under which it is possible to achieve significant results in the activities of both an individual person and the team as a whole. The scientist believes that "success is an experience of a state of joy, satisfaction because the result that a person aspired to in his activity either coincided with his expectations, hopes, or exceeded them. Based on this state, new, stronger motives for activity are being formed, and the levels of self-esteem and self-esteem are changing". In the case when success becomes steady, constant, a kind of reaction may begin, releasing the huge, hidden for the time being possibilities of the individual.

Belkin (1991) considers the success situation as one of the main methods of enhancing the learning process, as a targeted combination of psychological and pedagogical techniques that contribute to the conscious inclusion of each student in active learning activity, depending on individual capabilities, provide a positive emotional attitude of students to complete the educational task and an adequate perception of their results activities. The author believes that the basic condition for organizing a success situation is an atmosphere of goodwill. It can be concluded that Belkin analyzes the situation of success as a factor in the development of cooperative relations in the "teacher-student" system in the aspect of educational activity, i.e. suitable from an educational point of view, but just like other authors, does not consider the possibility of creating this situation in the aspect of extracurricular activities.

A success situation is one of the methods of organizing training, especially for students who are unable to cope with tasks on their own and need daily systematic help. This technique, according to the author, is based on one of the laws of development of feelings, it manifests itself in the fact that success inspires and inspires a person, increases interest in activities.

Schurkova (cited in Yasvin 2000) gives such a definition of a situation of success: "this is the living of the subject of his personal achievements in the context of the history of his personal life." The situation of success, according to the teacher, is always subjective, the result of efforts is regarded only in comparison with the result of yesterday's efforts, from the position of tomorrow's prospects of the individual. The purpose of a success situation is to initiate the physical and spiritual forces of the individual, to maximize the development of his abilities. A child, living a situation of success, gains dignity, discovers that he is at a certain level, at the same time, success generates satisfaction with life at the moment (Yasvin 2000).

After analyzing the main points of view on the use of the situation of success, we can conclude: the majority of educators, scientists consider the situation of success as a means of optimizing the learning process, while not affecting the possibility of applying this technique in the process of education. Teachers consider the situation of success in the context of school (teaching) work and, unfortunately, do not describe the possibility of using this technique in the context of extracurricular activities.

A success situation in the development of leadership qualities of adolescents is defined as a targeted combination of psychological and pedagogical techniques that contribute to the conscious inclusion of each adolescent in a specially organized activity aimed at gaining experience in leadership behavior depending on individual capabilities, provide a positive emotional attitude of adolescents to fulfill their tasks and adequate perception of the results of their activities.

Creating a situation of success for the adolescent will be effective in the case when the adolescent - the subject of activity is included in the activity designed by the teacher and implemented in it, showing its leadership qualities.

A situation of success only then becomes an effective means of developing a cooperative relationship between a teacher and students when it is represented by the whole variety of techniques and methods for its creation; implemented at each stage of interaction between the teacher and students, on the one hand, and at each stage of the educational activity, on the other; complicates the educational and educational tasks at each stage; 
implemented taking into account the characteristics and capabilities of each student in the organization of cognitive activity; facilitates the transfer of the educational process from the level of pedagogical impact and influence on the level of personal interaction with students, i.e. students adopting a subjective position in collaboration with the teacher (Larionova and Larionova 2014). Theoretical analysis made it possible to identify the structural components of a success situation:

The first component created by the teacher:

- the organization of activities that contribute to the maximum realization of leadership qualities in the greatest possible number of teenagers (in this case, such activity is work on the implementation of a social educational project);

- optimization of the style of relationships between members of the children's public association;

- creating an environment of cooperation.

$2^{\text {nd }}$ component:

- independent actions of adolescents aimed at solving certain problems.

Creating a situation of success during the work on the project ensures the development and implementation of the necessary qualities for those adolescents who have manifested themselves in the role of leaders and those who wish to become one. A situation of success can become a kind of "trigger" for the further movement of the individual.

3. Implementation of systematic pedagogical monitoring of the dynamics of leadership development of adolescents.

The effectiveness of leadership development is largely determined by how much the key moments of this development are explored, how correctly the teacher, diagnosing the situation, chooses the means of pedagogical influence, takes into account the current situation in the relationship of adolescents.

The teacher needs to know how developed the leadership qualities of the members of the children's public association, how they are implemented in relation to a particular situation. Systematic pedagogical monitoring helps to identify current and potential leaders, increase the activity of members of the children's public association. Studying the dynamics of the development of leadership qualities of adolescents in a children's public organization allows us to reveal the characteristics of the interaction of team members, to study the conditions for the development of personal initiative and initiative.

\section{Conclusions}

Thus, the conditions conducive to the effective development of leadership qualities of adolescents in a children's public organization in a multicultural environment were summarized and justified. Moreover, we showed that systematic involvement of adolescents in specially organized activities aimed at gaining leadership experience.

In addition, it appears that the use of social design technology in the activities of the children's public association with the provision of every teenager the opportunity to implement various positions of the association members (from the performer to the organizer) is very beneficial. Furthermore, our results demonstrate that the implementation of systematic pedagogical monitoring of the dynamics of the development of leadership qualities of adolescents in a children's public association might be useful and would bring some fruitful results if properly managed and arranged.

\section{References}

Andreev VI, Pedagogika: uchebny kurs dlya tvorcheskogo samorazvitiya, $1^{\text {st }}$ edn. (Centr innovacionnykh tekhnologiy: Kazan, 2000), 362 p.

Bauer E, Salavatova A, Shikhaliyev R (2018) The Educational Environment of the University as a Means of Preventing the Ideology of Extremism Among Young People. Advances in Social Science, Education and Humanities Research, 288: 216-219.

Belkin AS, Situaciya uspekha. Kak yeyo sozdat, $1^{\text {st }}$ edn. (Prosvescheniye: Moscow, 1991), 169 p. 
Borytko NM, V prostransve vospitatelnoy deyatelnosti. Monografiya, $1^{\text {st }}$ edn. (Peremena: Volgograd, 2001), 181 p.

Ibragimova L, Scobeleva I (2018) Conditions for creation and development of media culture in students of secondary professional education. Mediaobrazovaniye 1: 89-94.

Khushbatov A (2015) Terminologiya “pedagogicheskiye usloviya”. Molodoy ucheny 23: 1020-1022.

Krupskaya NK, O yunykh pionerakh, $1^{\text {st }}$ edn. (APN: Moscow, 1957), 264 p.

Larionova IA, Larionova SO (2014) Situaciya uspekha kak faktor razvitiya otnosheniy sotrudnichestva v sisteme "uchitel-uchenik". Sovremennye problemy nauki I obrazovaniya 6:6-8.

Pakhomov VP, Grazhdanskoye obrazovaniye v Rossii: novye podhody I regionalny opyt. Vserossiyskaya akciya "Ya grazhdanin Rossii": rukovodstvo dlya organizatororv I metodistov, $1^{\text {st }}$ edn. (NTC: Moscow-Samara, 2000), $66 \mathrm{p}$.

Platonov KK, Adaskin BI, Ob izmenenii I formirovanii lichnosti uchaschikhsya, $1^{\text {st }}$ edn. (Nauka: Moscow, 1996), pp. 5-6

Pogrebnaya IA, Mikhailova SV, Ibragimova LA (2019) Formation of readiness and motivation of students for independent work in higher technical educational institution. Amazonia investiga 8 (21): 483-490.

Vygotsky LS, Razvitiye vysshikh psikhicheskikh funkciy, $1^{\text {st }}$ edn. (APN: Moscow, 1960), 500 p.

Yasvin VA, Ekspertiza shkolnoy obrazovatelnoy sredy, $1^{\text {st }}$ edn. (Sentyabr: Moscow, 2000) 128 p. 